\title{
Mittelohr: mehr Komplikationen bei Rauchern
}

\author{
Neben den bekannten negativen Effekten des Rauchens gehören einer \\ aktuellen Studie zufolge auch Risiken im Bereich des Mittelohrs. Die gute \\ Nachricht: Durch langjährige Tabakabstinenz sinkt dieses Risiko wieder.
}

n einer retrospektiven Auswertung untersuchten US-amerikanische Hals-Nasen-Ohrenärzte, ob der Rauchstatus einen Effekt auf die Ergebnisse 1.531 ohrchirurgischer Eingriffe an 1.183 Patienten in ihrer Klinik hatte. Dabei unterschieden sie aktive Raucher $(21 \%)$ von Patienten mit früherem Tabakkonsum (mindestens seit einem Monat Rauchstopp, 5\%) und lebenslange Nichtraucher (63\%). Der jüngste Raucher war zwölf Jahre alt. Bei $11 \%$ war der Rauchstatus retrospektiv nicht mehr festzustellen, sie wurden von den nachfolgenden Analysen ausgeschlossen. Die postoperative Nachbeobachtungszeit betrug zwölf Monate.

Bei den aktiven Rauchern fanden die Operateure Cholesteatome signifikant häufiger als bei Nichtrauchern. Auch Rezidive von Cholesteatomen kamen bei den Rauchern häufiger vor, zudem musste bei ihnen häufiger eine Rekonstruktion der Gehörknöchelchenkette oder eine Mastoidektomie vorgenommen werden. Komplikationen wie Fisteln oder Transplantatverlust und nachfolgende Revisionsoperationen waren bei Tabakabhängigkeit öfter nötig als bei Nichtrauchern. Diese Unterschiede spiegelten sich auch im Hörergebnis nach zwölf Monaten wieder: Es fiel bei den Rauchern signifi- kant schlechter aus als bei Nichtrauchern. Auch bei den ehemaligen Rauchern rekonstruierten die Operateure häufiger die Gehörknöchelchenkette als bei Nichtrauchern. Allerdings waren die Ergebnisse jener Leute, die vor mehr als fünf Jahren aufgehört hatten, mit denen der Nichtraucher vergleichbar. Dagegen entsprachen die Ergebnisse derjenigen, deren rauchfreie Zeit noch weniger als fünf Jahre betrug, denen der Raucher.

Fazit: Chronische Mittelohrerkrankungen sind bei Rauchern signifikant ausgeprägter als bei Nichtrauchern, sodass die Chirurgie häufig umfangreicher erfolgen muss und das Hörergebnis schlechter ausfällt. Das Komplikationsrisiko ist erhöht, Revisionen sind häufiger nötig. Wer mit dem Rauchen aufhört, erreicht in Bezug auf das Mittelohr wahrscheinlich nach fünf Jahren wieder die geringere Risikokonstellation eines Nichtrauchers. Das sollten HNO-Ärzte berücksichtigen und ihre Patienten zur Aufgabe des Rauchens ermutigen. fk

Kaylie DM et al. Effects of smoking on otologic surgery outcomes.

Laryngoscope 2009; 119: 1384-90.

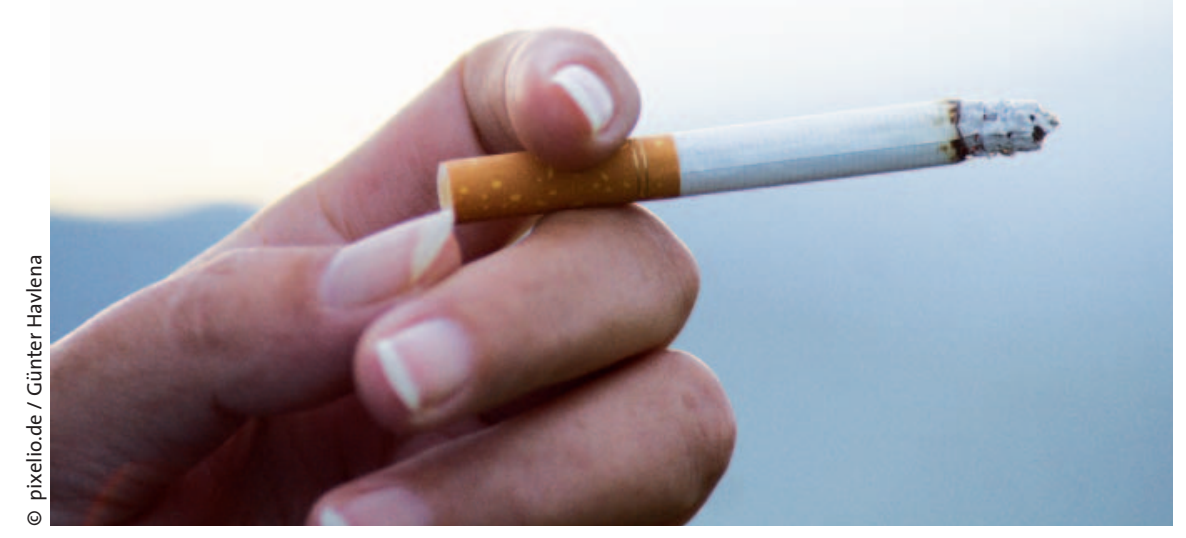

Rauchen geht mit einem erhöhten Risiko für chronische Mittelohrerkrankungen einher. 